\title{
Central processing uncertainty as a determinant of choice reaction time*
}

\author{
GEORGE E. BRIGGS $\dagger$ \\ New Mexico State University, Las Cruces, New Mexico 88003 \\ and \\ ARTHUR M. JOHNSEN and DAVID SHINAR \\ Ohio State University, Columbus, Ohio 43210
}

\begin{abstract}
It was demonstrated that central processing uncertainty $\left(\mathrm{H}_{\mathrm{c}}\right)$ can be derived to provide a single valued statement of the information hypothesis $\mathrm{RT}=a+b\left(\mathrm{H}_{c}\right)$ across test stimulus sets and across several levels of test stimulus probability in an information reduction task. The derivation procedure assumes successive tests of stimulus hypotheses with Bayesian revision of stimulus probabilities after failure of an initial test. It was shown that the procedure can be generalized to data from single test stimuli in an information conservation task. Stimulus and response repetition effects were estimated for the information reduction task data.
\end{abstract}

In the information reduction task he developed, Sternberg (1966) has proposed that the subject engages in an exhaustive comparison of encoded test stimulus information against the $\mathrm{M}$ positive set stimuli, memorial information on the negative set essentially being ignored in this stimulus classification process. In terms of the Smith (1968) paradigm of human information processing, the additivity statement used by Sternberg

$$
\mathrm{RT}=\mathrm{a}+\mathrm{b}(\mathrm{M})
$$

may be interpreted as follows: the intercept constant a represents the time required to carry out both initial stimulus encoding and the subsequent response decoding functions, while the slope constant $b$ represents the time per positive set stimulus required to carry out the stimulus classification function at a central level of processing.

Swanson and Briggs (1969) first noted that there may be a curvilinear relationship between $R T$ and $M$, not a linear relationship as indicated by Eq. 1. They proposed a Shannon (1948) expression for central processing uncertainty $\left(\mathrm{H}_{\mathrm{c}}\right)$ :

$$
\mathrm{H}_{\mathbf{c}}=-\Sigma \mathrm{p}_{\mathrm{i}} \log _{2} \mathrm{p}_{\mathrm{i}}
$$

as the predictor variable in the additivity statement

$$
R T=a+b\left(H_{c}\right) \text {. }
$$

\footnotetext{
*This research was conducted at Ohio State University and was funded in part by the National Science Foundation through Grant GN-534.1 from the Office of Scientific Information Service to the Computer and Information Science Research Center of the University.

†R eprint requests: George E. Briggs, Psychology Department, Box 3452, New Mexico State University, Las Cruces, New Mexico 88003 .
}

Equation 2 is interpreted as the average amount of uncertainty which must be resolved in order to classify a test stimulus as to positive set status. The value of $\mathrm{H}_{\mathrm{c}}$ is dependent upon the explicit definition of an exhaustive set of $n$ possible outcomes each with a probability $p_{i}$. Obviously, how one defines the set of $n$ possible outcomes is critical here. Briggs and Swanson (1970) validated a particular way of utilizing Eq. 2 for the permanently fixed set version of the Sternberg task. To illustrate, consider the $M=2$ case with each of the two positive set stimuli $\left(S_{1}\right.$ and $\left.S_{2}\right)$ equally probable and with the probability of negative set stimuli $\mathrm{p}(\mathrm{N})=.5$. Thus $\mathrm{p}\left(\mathrm{S}_{1}\right)=\mathrm{p}\left(\mathrm{S}_{2}\right)=.25$. The results of Briggs and Swanson indicate that it is valid to use these three stimulus categories, $\mathrm{S}_{1}, \mathrm{~S}_{2}$, and $\mathrm{N}$, and thereby calculate $\mathrm{H}_{\mathrm{c}}=.5+.5+.5=1.5$ bits from Eq. 2 .

Later Briggs and Johnsen (1973) examined the way one should utilize Eq. 2 to calculate $\mathrm{H}_{\mathrm{c}}$ values for the varied set version of the Sternberg task. From their results, it appears that when confronted with the varied set procedure the $S$ utilizes a somewhat more involved central processing procedure than in the permanently fixed set situation. Specifically, for the $M=2$ condition, their results indicate that four stimulus categories are justified: $S_{1}, S_{2}, N_{1}$, and $N_{2}$. Further, it appears that in the equiprobable situation used by Briggs and Johnsen, $\mathrm{p}\left(\mathrm{S}_{1}\right)=\mathrm{p}\left(\mathrm{N}_{1}\right)=\mathrm{p}\left(\mathrm{S}_{2}\right)=\mathrm{p}\left(\mathrm{N}_{2}\right)=.25$. Thus $\mathrm{H}_{\mathrm{c}}=.5+.5$ $+.5+.5=2.0$ bits.

It follows from the above that in the varied set situation the subject utilizes information on subsets of the negative set in his attempt to determine if the encoded test stimulus is a member of the positive set. However, in the fixed set condition, it appears that the subject treats the negative set as an undifferentiated set.

The present research utilized the varied set version of the Sternberg task in an attempt to explore the 
possibility that one can extend the use of $\mathrm{H}_{\mathrm{c}}$ to account for intercept differences when Eq. 3 is fit to data from different experimental conditions. As indicated above, in the past one would consider intercept differences as being due to encoding and/or decoding processes, not central processing. However, consider the usual (but not universal) finding that when either Eq. 1 or 3 is fit to data from the Sternberg task, the negative set function is parallel to the positive set function but slower by an average of 40 to $50 \mathrm{msec}$. From the additive factor concept of Sternberg (1969) one would conclude that, since there is no interaction between stimulus set and $\mathrm{M}$, the difference in reaction time is due to encoding and/or decoding, not central processing. However, it is conceivable that the 40 - to $50-\mathrm{msec}$ difference involves only a fixed extra time at central processing, as suggested by Briggs and Johnsen (1973) in their rechecking concept, i.e., the subject first tests the positive set hypothesis and, if it is supported, decodes a match response; however, if the first test fails, he then tests (rechecks) the negative set hypothesis. Thus, central processing functions, not the decoding function, may account for the intercept differences between positive and negative set data in the Sternberg task if one assumes a successive testing procedure with self-terminating processing between (but not within) tests.

The present study was concerned also with stimulus probability effects. While the available data are somewhat sparse, it does appear from Theios, Smith, Haviland, Traupmann, and Moy (1973) that variation in stimulus probability within the positive set, $\mathrm{p}\left(\mathrm{S}_{\mathfrak{i}}\right)=.15$ vs $p\left(S_{j}\right)=.05$, results in parallel functions relating $R T$ to $M$. In that study, there also was variation in stimulus probability within the negative set, and while the RT vs $M$ functions are somewhat irregular, it does appear that they too are essentially parallel for the $p\left(\mathrm{~N}_{\mathrm{i}}\right)=.15$ and the $\mathrm{p}\left(\mathrm{N}_{\mathrm{j}}\right)=.05$ conditions. Again, from the additive factor concept, one could ascribe the intercept differences due to stimulus probability as being a function of encoding and/or decoding times. However, Theios et al (1973) and Theios (1973) argue persuasively that a self-terminating memory scanning (central) process can account for the probability effects.

Theios et al utilized the fixed set version of the Sternberg task. The present study employed the varied set version, and thus we can explore an extension of their interpretation to data from a version of the task which Briggs and Johnsen (1973) have found to involve more complex central processing than does the fixed set version.

\section{METHOD}

\section{Subjects}

The subjects were 80 right-handed undergraduate students ( 35 males and 45 females) who responded to an ad in the campus newspaper. They participated for five consecutive daily sessions of $30 \mathrm{~min}$ each. Payment consisted of $\$ 1.25$ per session plus a bonus (see below).

\section{Procedure and Apparatus}

A varied set version of the Sternberg (1966) task was employed. At the beginning of each block of trials, the experimenter read a list of two, three, or four letters of the alphabet. The subject repeated the positive set, and to each test stimulus in the subsequent block he emitted either a match or a no-match response via depression of one or the other of two buttons on which he rested his index fingers. Assignment of fingers to the buttons was counterbalanced across (not within) subjects. The composition of the positive set was changed before each block of trials. The letters A, B, D, G, H, I, J, K, Q, and Y were utilized, and if a letter was not assigned to the positive set, it served as a negative set item. A test stimulus consisted of a single letter back-projected on a display screen $55 \mathrm{~cm}$ before the subject. The letters had been drawn from the Leroy standard template, photographed on $35-\mathrm{mm}$ film, and mounted in $2 \mathrm{x}$ 2 in. slides. A Kodak Carousel RA950 random access projector displayed the test stimuli, which appeared black on a light field. An electronic timer, accurate to $1 \mathrm{msec}$, started with stimulus onset and stopped with the subject's response. Both the reaction time and the response emitted were recorded by a Hewlett-Packard digital recorder, Model 562A.

The subject received instructions and positive set information via a headset. When not in communication with the experimenter, the subject heard white noise at $80 \mathrm{~dB}$ over the headset. Each trial consisted of the following sequence of events: (1) a warning signal occurred as a brief interruption of the white noise $500 \mathrm{msec}$ before test stimulus onset, (2) a test stimulus appeared for $2 \mathrm{sec}$ and a response was emitted during this period, and (3) an intertrial interval of $3.5 \mathrm{sec}$ occurred prior to the next warning signal. An Iconix timer, Model 6255, controlled the sequence of events. Following each block of 32 trials, the subject was informed whether his performance was too slow, too fast, or within an acceptable range of reaction time. Although he was unaware of it, this feedback was based on the subject's error rate, one to three errors per block being acceptable. A $10 \mathrm{c}$ bonus was paid for each acceptable block of trials.

\section{Design}

There were four groups of 20 subjects each. Group $M=2 E$ experienced two letters in the positive set, and each letter was equally probable, $p\left(S_{1}\right)=p\left(S_{2}\right)=.25$. Group $M=4 E$ experienced four letters in the positive set, and, as with Group $M=2 E$, each letter was equally probable, $p\left(S_{i}\right)=.125$. Groups $M=3 U$ and $M=4 U$ had three and four letters, respectively, in their positive sets, but one letter occurred more frequently $\left(S_{F}\right)$ than the others $\left(\mathrm{S}_{I}\right)$. Prior to each block these subjects were informed which one of the three or four stimuli in the positive set would serve as the $S_{F}$ stimulus. For Group $M=3 U, p\left(S_{F}\right)=$ .375 , while each of the two $S_{I}$ stimuli occurred with $p\left(S_{I}\right)=$ .0625 . For Group $\mathrm{M}=4 \mathrm{U}, \mathrm{p}\left(\mathrm{S}_{F}\right)=.3125$, while each of the other three stimuli occurred with $p\left(S_{I}\right)=.0625$. For all groups, the probability of a negative set stimulus was $\mathrm{p}(\mathrm{N})=.5$.

Within each daily session there were four blocks of 32 test trials each. Across the five sessions each subject experienced all 10 letters in the positive sets with counterbalancing across sessions and across subjects. The first two sessions were considered practice to familiarize the subject with the relative frequencies of occurrence of the positive set stimuli. The data reported below came from the final three sessions.

\section{Central Processing Uncertainty}

A value of central processing uncertainty $\left(\mathrm{H}_{c}\right)$ was calculated for each group from Eq. 2 following the procedure developed by Briggs and Johnsen (1973) for the varied set version of the Sternberg task. These four values are listed in Table 1 . They were used to define the scale values of the predictor variable in plotting average reaction times for positive and negative set stimuli (see Fig. 1). 


\section{RESULTS}

Table 2 provides a summary of the average correct response reaction time data and of the probability of errors (1) by stimulus set (left portion of the table) and (2) by frequent vs infrequent positive set stimuli (right portion). Consider first the error data as listed in Column 3. As an example, across the 20 subjects in Group $\mathrm{M}=2 \mathrm{E}$ there were 7,680 trials, but due to mechanical failures, 7,536 responses were measured. Of this number, 183 were incorrect no-match responses (false negatives) and 155 were incorrect match responses (false positives). Thus, $\mathrm{p}(\mathrm{E})=183 / 7,536=.0243$ for those trials on which a positive set stimulus was presented and $\mathrm{p}(\mathrm{E})=155 / 7,536=.0206$ for negative set trials.

Two features may be noted from Column 3: (1) while the error rates are low, there is a progressive increase in such rates from Group $M=2 E$ through Group $M=4 E$; and (2) the error rates for negative set stimuli are consistently lower than for positive set stimuli, as a class. Both of these results are common to studies utilizing the Sternberg task. Briggs and Johnsen (1973) have utilized the latter finding to support the suggestion that, in this task, the subject first tests the positive set hypothesis and, if this fails, then tests the negative set hypothesis. One would expect less error in situations where encoded stimulus information is subjected to two cycles of testing than when it is tested only once for a match to memorial representations of potential test stimuli.

The concept of successive testing cycles will be elaborated further in this paper, and Column 6 of Table 2 provides information which will be used in that elaboration. Listed there are the conditional probabilities of error given the presentation of a particular stimulus or stimulus set. Consider the three

Table 1

The Basis for Calculating $\mathrm{H}_{\mathrm{c}}$ from Equation 2 for Each Group

\begin{tabular}{cc}
\hline Group $M=2 E$ & Group $M=3 \mathrm{U}$ \\
\hline $\mathrm{p}\left(\mathrm{S}_{2}\right)=.25$ & $\mathrm{p}\left(\mathrm{S}_{\mathrm{F}}\right)=.375$ \\
$\mathrm{p}\left(\mathrm{N}_{2}\right)=.25$ & $\mathrm{p}\left(\mathrm{S}_{\mathrm{I}}\right)=.0625$ \\
$\mathrm{p}\left(\mathrm{S}_{2}\right)=.25$ & $\mathrm{p}\left(\mathrm{S}_{\mathrm{I}}\right)=.0625$ \\
$\mathrm{p}\left(\mathrm{N}_{2}\right)=.25$ & $\mathrm{p}\left(\mathrm{N}_{\mathrm{F}}\right)=.375$ \\
& $\mathrm{p}\left(\mathrm{N}_{\mathrm{I}}\right)=.0625$ \\
& $\mathrm{p}\left(\mathrm{N}_{\mathrm{I}}\right)=.0625$ \\
$\mathrm{H}_{\mathrm{c}}=2.0$ & $\mathrm{H}_{\mathrm{c}}=2.0612$ \\
\hline $\mathrm{Group} \mathrm{M}=4 \mathrm{U}$ & $\mathrm{Group} \mathrm{M}=4 \mathrm{E}$ \\
\hline $\mathrm{p}\left(\mathrm{S}_{\mathrm{F}}\right)=.3125$ & $\mathrm{p}\left(\mathrm{S}_{1}\right)=.125$ \\
$\mathrm{p}\left(\mathrm{S}_{\mathrm{I}}\right)=.0625$ & $\mathrm{p}\left(\mathrm{S}_{2}\right)=.125$ \\
$\mathrm{p}\left(\mathrm{S}_{\mathrm{I}}\right)=.0625$ & $\mathrm{p}\left(\mathrm{S}_{3}\right)=.125$ \\
$\mathrm{p}\left(\mathrm{S}_{\mathrm{I}}\right)=.0625$ & $\mathrm{p}\left(\mathrm{S}_{4}\right)=.125$ \\
$\mathrm{p}\left(\mathrm{N}_{\mathrm{F}}\right)=.3125$ & $\mathrm{p}\left(\mathrm{N}_{1}\right)=.125$ \\
$\mathrm{p}\left(\mathrm{N}_{\mathrm{I}}\right)=.0625$ & $\mathrm{p}\left(\mathrm{N}_{2}\right)=.125$ \\
$\mathrm{p}\left(\mathrm{N}_{\mathrm{I}}\right)=.0625$ & $\mathrm{p}\left(\mathrm{N}_{3}\right)=.125$ \\
$\mathrm{p}\left(\mathrm{N}_{\mathrm{I}}\right)=.0625$ & $\mathrm{p}\left(\mathrm{N}_{4}\right)=.125$ \\
$\mathrm{H}_{\mathrm{c}}=2.5488$ & $\mathrm{H}_{\mathrm{c}}=3.0$ \\
\hline
\end{tabular}

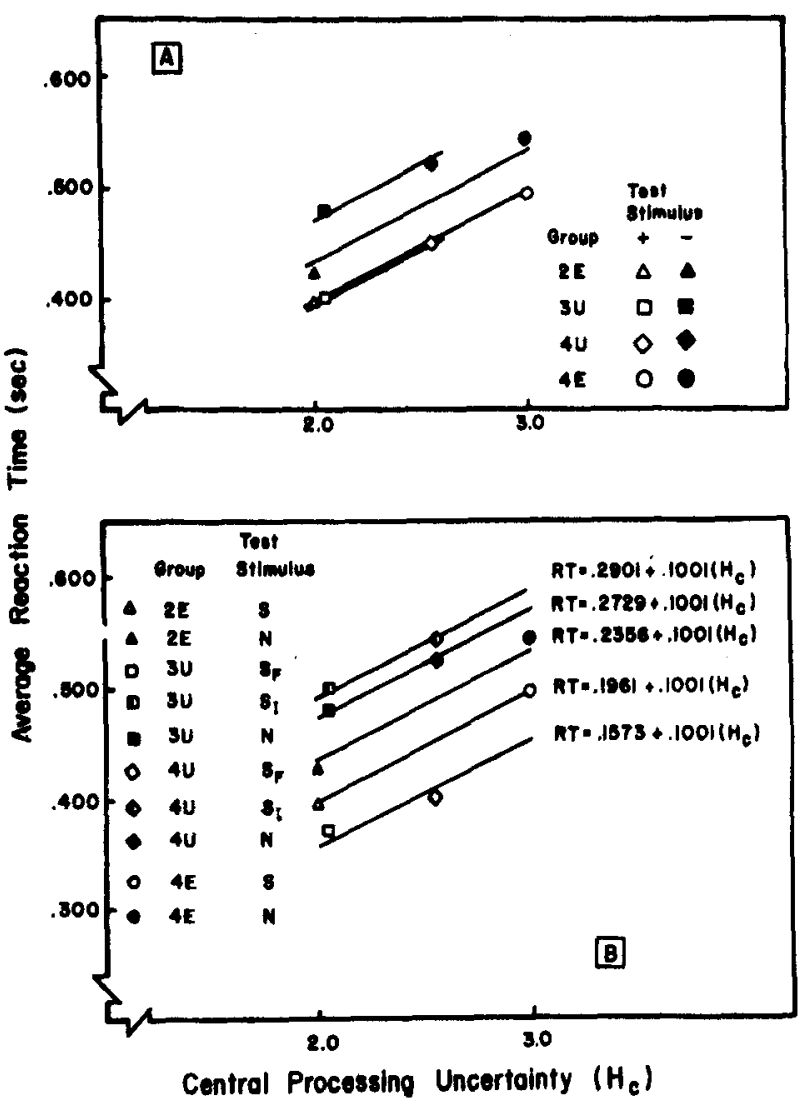

Fig. 1. Reaction time as a function of central processing uncertainty.

Table 2

Reaction Time (in Seconds) and Error Probabilities by Groups and by Stimulus Set

\begin{tabular}{cccccc}
$\begin{array}{c}\text { Stimulus } \\
\text { Set }\end{array}$ & RT & $\mathrm{p}(\mathrm{E})$ & $\begin{array}{c}\text { Stimulus } \\
\text { Set }\end{array}$ & $\mathrm{RT}$ & $\begin{array}{l}\mathrm{p}\left(\mathrm{E} \mid \mathrm{S}_{\mathrm{i}}\right. \\
\text { or } \mid \mathrm{N})\end{array}$ \\
\hline & \multicolumn{5}{c}{ Group $\mathrm{M}=2 \mathrm{E}$} \\
$\mathrm{S}$ & .3963 & .0243 & $\mathrm{~S}$ & .3963 & .0484 \\
$\mathrm{~N}$ & .4277 & .0206 & $\mathrm{~N}$ & .4277 & .0413 \\
& & Group M $=3 \mathrm{U}$ & & \\
$\mathrm{S}$ & .3988 & .0255 & $\mathrm{~S}_{\mathrm{F}}$ & .3729 & .0088 \\
$\mathrm{~N}$ & .4818 & .0218 & $\mathrm{~S}_{\mathrm{I}}$ & .4984 & .1838 \\
& & & $\mathrm{~N}$ & .4818 & .0438 \\
$\mathrm{~S}$ & .4511 & .0283 & $\mathrm{~S}_{\mathrm{F}}$ & .4032 & .0151 \\
$\mathrm{~N}$ & .5254 & .0234 & $\mathrm{~S}_{\mathrm{I}}$ & .5432 & .1271 \\
& & & $\mathrm{~N}$ & .5254 & .0470 \\
$\mathrm{~S}$ & .4964 & .0348 & $\mathrm{~S}$ & .4964 & .0693 \\
$\mathrm{~N}$ & .5439 & .0287 & $\mathrm{~N}$ & .5439 & .0577 \\
\hline
\end{tabular}

entries for Group $\mathrm{M}=3 \mathrm{U}$. It may be recalled that one of the three positive set stimuli occurred within a block of 32 test trials with $p=.375$, while the other two stimuli each occurred with $p=.0625$. Of the 2,852 usable trials in which the most frequent stimulus $\left(\mathrm{S}_{\mathrm{F}}\right)$ occurred, the subjects incorrectly emitted a no-match response on 25 trials; thus $\mathrm{p}\left(\mathrm{E} \mid \mathrm{S}_{\mathrm{F}}\right)=25 / 2,852=.0088$. Likewise, of the 903 usable trials on which either of the two infrequent positive set stimuli $\left(S_{I}\right)$ occurred, 166 
responses were in error; thus $p\left(E \mid S_{I}\right)=166 / 903=$ .1838. Finally, there were 3,723 usable trials on which some negative set stimulus occurred and 163 of the responses were false positives; thus $p(E \mid N)=163 / 3,723$ $=.0438$.

Before using the conditional error rate data, it is necessary to examine the evidence for a successive testing cycle strategy by the subjects. This evidence is contained in the reaction time data trends across groups. Consider first the average times across all stimuli within the positive and the negative sets (see Column 2 of Table 2). This information is shown in Fig. 1A where the scale values of central processing uncertainty $\left(\mathrm{H}_{c}\right)$ are those specified in Table 1 . It is apparent that a single linear function could describe the relationship between the correct positive reaction time data and $\mathrm{H}_{c}$ for all four groups. However, the times for Groups $\mathrm{M}=3 \mathrm{U}$ and $M=4 U$ are averaged across both the frequent and the infrequent positive set stimuli, and it will be seen shortly that stimulus frequency resulted in a pronounced effect on reaction time. Therefore, it is preferable to fit a linear function only to the positive set data of Groups $M=2 E$ and $\mathrm{M}=4 \mathrm{E}$. The fit yields the equation $\mathrm{RT}=.1961+$ $.1001\left(\mathrm{H}_{\mathrm{c}}\right)$.

A linear function was then fit to the positive set data of Groups $M=3 U$ and $M=4 U$ using the same slope constant as noted above. The result is $\mathrm{RT}=.1942+$ $.1001\left(\mathrm{H}_{\mathrm{c}}\right)$, and this fit is quite good, the standard error of prediction being only $1.8 \mathrm{msec}$. Finally, the same slope constant was used to fit the negative set data of Groups $M=2 E$ and $M=4 E$ and separately to fit the negative set data of Groups $M=3 U$ and $M=4 U$. The results are $\mathrm{RT}=.2356+.1001\left(\mathrm{H}_{\mathrm{c}}\right)$ and $\mathrm{RT}=.2729+$ $.1001\left(\mathrm{H}_{\mathrm{c}}\right)$ with standard errors of prediction of 8.1 and $2.6 \mathrm{msec}$, respectively. The parallel fits of the negative set data are justified by the results of two analyses of variance, one to the positive and negative set reaction times of Groups $M=2 E$ and $M=4 E$ and the second to comparable data from Groups $M=3 U$ and $M=4 U$. In neither analysis was there statistical evidence of an interaction of Stimulus Set by Groups, $\mathrm{p}>.05$.

It follows from these equations that, on the average, it took $39.5 \mathrm{msec}$ longer to emit a no-match than a match reaction in Groups $M=2 E$ and $M=4 E$. Further, the no-match reactions of Groups $M=3 U$ and $M=4 U$ were even more delayed, the average time being $78.7 \mathrm{msec}$ longer than for a match reaction by these subjects. This greater time delay suggests that Groups $M=3 U$ and $M=4 U$ engaged in a more involved testing of the alternative hypotheses, following an initial test of the positive set hypothesis, than did Groups $\mathrm{M}=2 \mathrm{E}$ and $M=4 E$.

The possible nature of this more involved testing schedule is illustrated in Fig. 1B. There the reaction time data of Table 2, Column 5, are provided. It will be noted that within Groups $M=3 U$ and $M=4 U$ the reaction times to the most frequent positive set stimulus were substantially faster than would be predicted from the linear equation presented above for the positive set data of Groups $\mathrm{M}=2 \mathrm{E}$ and $\mathrm{M}=4 \mathrm{E}: \mathrm{RT}=.1961+.1001$ $\left(H_{c}\right)$. In Fig. 1B, parallel fits of the $S_{F}$ and $S_{I}$ data are listed along with the parallel fits to the negative set data as reported above. On the average, a correct response to an $\mathrm{S}_{\mathrm{F}}$ stimulus was emitted $58.3 \mathrm{msec}$ sooner than a response to an equally probable (S) stimulus (Groups $M=2 E$ and $M=4 E$ ), but a response to an $S_{I}$ stimulus required $74.4 \mathrm{msec}$ longer than did a response to an $S$ stimulus, on the average. Indeed, a reaction to an $S_{I}$ stimulus was slower than a correct reaction to the negative set stimuli $(\mathrm{N})$ by an average of $17.2 \mathrm{msec}$ within Groups $M=3 U$ and $M=4 U$. This pattern of results suggests that these groups first tested the $S_{F}$ hypothesis, then the $\mathrm{N}$ hypothesis (if necessary), and finally, if neither of the first two tests was successful, there was a test of the $S_{I}$ hypothesis. The consequences of such a testing schedule will be explored in the discussion section.

\section{Repetition Data}

In the Sternberg information reduction task, one can distinguish three possible types of positive set stimulus events when comparing Trial $n$ with Trial $n-1$ : (1) the same positive set stimulus occurs on both trials (Id), (2) two different stimuli occur on the two trials but both are from the positive set (Eq), or (3) a negative set stimulus occurs on Trial $n-1$ and a positive set stimulus occurs on Trial $n$ (Diff). Likewise, the same three possible transition outcomes hold for pairs of trials when a negative set stimulus is considered on Trial $n$. In the Id situation there are both stimulus repetition and response repetition; in situation $\mathrm{Eq}$ there is stimulus nonrepetition but response repetition; and in the Diff situation there is neither stimulus nor response repetition.

Within each group of subjects the stimulus sequences were classified as to the three possible transition situations, and average correct reaction times were calculated separately to positive and to negative set stimuli on Trial $\mathbf{n}$. The results are listed in Table 3. Consider reactions to the positive set stimuli. First, Id reactions were faster than $\mathrm{Eq}$ reactions for all groups. This is a common, though not universal, result (see Kornblum, 1973). Second, Diff reactions were faster than Id reactions in all but one set of data (Group $M=4 \mathrm{E}$ ). This second observation is rather unusual (again see Kornblum, 1973), although it is not without precedent (see the two-choice results of Experiments I and II by Schvaneveldt \& Chase, 1969). The results in Table 3 for reactions to negative set stimuli show that once again Diff reactions were the fastest; however, here the Eq reactions were faster than Id reactions in all but one case (Group M $=4 \mathrm{U}$ ).

In considering the above results it should be noted that stimulus repetition was a rather rare event in this study. Across both the positive and negative set trials the probability of a stimulus repetition was only $p(R)=.10$ 
on the average. Thus the probability of stimulus nonrepetition (Eq plus Diff) was $\mathrm{p}(\mathrm{NR})=.90$. The data of Kornblum (1969, see his Fig. 3) indicate that under this rather extreme difference between $p(R)$ and $p(N R)$, stimulus nonrepetition reactions (and thus Diff reactions) should be faster than stimulus repetition reactions (Id).

A second observation from Table 3 is that while the reaction times to negative set stimuli increase systematically with increases in central processing uncertainty $\left(\mathrm{H}_{c}\right)$ as derived for the four groups (see Table 1), there is a nonmonotonic ordering of reaction times across the same $\mathrm{H}_{c}$ values for the positive set data. This is because the positive set data for Groups $M=3 \mathrm{U}$ and $M=4 U$ were restricted to the most frequent stimuli, and as may be recalled from Fig. $1 \mathrm{~B}$, the $\mathrm{S}_{\mathrm{F}}$ times were faster on the average than were the positive set reactions of Groups $M=2 E$ and $M=4 E$. The positive set data of Table 3, then, are consistent with the bottom two functions of Fig. 1B. If the subsequent attempt to specify $H_{c}$ values for successive hypothesis testing is successful, it should permit a parsimonious description not only of the overall average reaction times of Fig. 1B, but also it should describe accurately the repetition and nonrepetition data of Table 3.

\section{DISCUSSION}

Briggs and Johnsen (1973) validated the way $\mathrm{H}_{c}$ values should be calculated for the varied set version of the Sternberg task. It is apparent from Fig. 1 A that the $\mathrm{H}_{c}$ values so calculated for the present study (see Table 1) quite adequately describe the relationship between reaction time and central processing uncertainty for the positive set stimuli as a class. However, a single valued linear function no longer describes the $\mathrm{RT}-\mathrm{H}_{\mathrm{c}}$ relationship when one examines $S_{I}$ and $S_{F}$ reaction times separately. The strategy adopted by the authors was to derive a procedure for calculating values of $H_{c}$ for the $S_{F}, S_{I}$, and $N$ stimulus conditions illustrated in Fig. $1 \mathrm{~B}$ such that all 10 data points could be reasonably well fit by the equation $\mathrm{RT}=$ $.1961+.1001\left(\mathrm{H}_{\mathrm{c}}\right)$, which describes the additivity relationship for the $S$ stimuli of Groups $M=2 E$ and $M=4 E$. It will be seen that this is a post hoc strategy and that it involves several assumptions, none of which are testable by the present data. The value of this approach, then, is that the empirical description so obtained should indicate the nature of the behavioral theory needed to account for information processing in a choice reaction task; it is not a test of such a theory.

It is assumed that after test stimulus encoding, the subject engages in a series of hypothesis tests starting with the positive set hypothesis. It is assumed that the a priori stimulus probabilities determine which positive set hypothesis is tested first as well as the order of the subsequent tests (should the initial test fail). It is assumed that while the a priori stimulus probabilities
Table 3

Average Correct Reaction Times (Seconds) for Groups, Repetition Conditions, and Stimulus Sets

\begin{tabular}{|c|c|c|c|c|c|c|}
\hline \multirow[b]{2}{*}{ Group } & \multicolumn{3}{|c|}{ Positive Set } & \multicolumn{3}{|c|}{ Negative Set } \\
\hline & Id & $\mathrm{Eq}$ & Diff & Id & $\mathrm{Eq}$ & Diff \\
\hline $\mathrm{M}=2 \mathrm{E}$ & .412 & .421 & .387 & .479 & .455 & .414 \\
\hline $\mathrm{M}=3 \mathrm{U}$ & .381 & .400 & .366 & .521 & .496 & .471 \\
\hline$M=4 U$ & .416 & .425 & .394 & .539 & .539 & .519 \\
\hline$M=4 E$ & .464 & .514 & .495 & .576 & .566 & .533 \\
\hline
\end{tabular}

define the central processing uncertainty present on the first hypothesis test, revised probabilities given failure of the first test are needed to define the uncertainty level present on a subsequent test. The Bayesian probability revision equation was employed for this purpose. Finally, it is assumed that such hypothesis testing is self-terminating between but not within tests. Table 4 contains a summary of the procedures used to calculate the several $\mathrm{H}_{\mathrm{c}}$ values, given the above assumptions.

\section{Groups $M=2 E$ and $M=4 E$}

Only two tests are needed to account for the positive and negative reaction time data in those cases where stimuli within the positive set are equally probable. As may be seen in Table 4 , the uncertainty present on Test 1 is determined by the a priori stimulus probabilities according to the summation procedure of Eq. 2 which was validated by Briggs and Johusen (1973) for positive set reaction time data. These values are $\mathrm{H}_{\mathbf{c}}$ $=2.0$ and 3.0 bits for Groups $M=2 \mathrm{E}$ and $M=4 \mathrm{E}$, respectively. Test 2 for each group is concerned with the negative set hypothesis, given a failure (no-match or $\mathrm{NM}_{1}$ ) of Test 1 . The Bayes equation

$$
\mathrm{p}\left(\mathrm{S} \mid \mathrm{NM}_{1}\right)=\frac{\mathrm{p}\left(\mathrm{NM}_{1} \mid \mathrm{S}\right) \mathrm{p}(\mathrm{S})}{\mathrm{p}\left(\mathrm{NM}_{1} \mid \mathrm{S}\right) \mathrm{p}(\mathrm{S})+\mathrm{p}\left(\mathrm{NM}_{1} \mid \mathrm{N}\right) \mathrm{p}(\mathrm{N})}
$$

was used to revise the positive set probabilities. It may be noted in Table 4 that the numerical values of $\mathrm{p}\left(\mathrm{NM}_{1} \mid \mathrm{S}\right)$ are the contingent probabilities of error listed in Table 2, Column 6, for the positive set stimuli. The values of $p\left(\mathrm{NM}_{1} \mid \mathrm{N}\right)$ are 1 - contingent error for the negative set stimuli, as listed in Table 2 . The values of central processing uncertainty for Test 2 , then, are $\mathrm{H}_{\mathbf{c} 2}=.2779$ and .3622 bit for Groups $\mathrm{M}=2 \mathrm{E}$ and $M=4 E$, respectively. Since reactions to negative set stimuli involve the time to consider both the positive and the negative set hypotheses, the total uncertainty is $\mathrm{H}_{\mathrm{c} 12}=\mathrm{H}_{\mathrm{c} 1}+\mathrm{H}_{\mathrm{c} 2}=2.2779$ and 3.3622 bits for the two groups, respectively.

\section{Groups $M=3 \mathrm{U}$ and $M=4 \mathrm{U}$}

It may be noted from Table 4 that three successive tests are required to account for the reaction time data when stimuli, within the positive set are unequally probable. In these situations, it appears that Test 1 is concerned primarily with the most probable positive set 


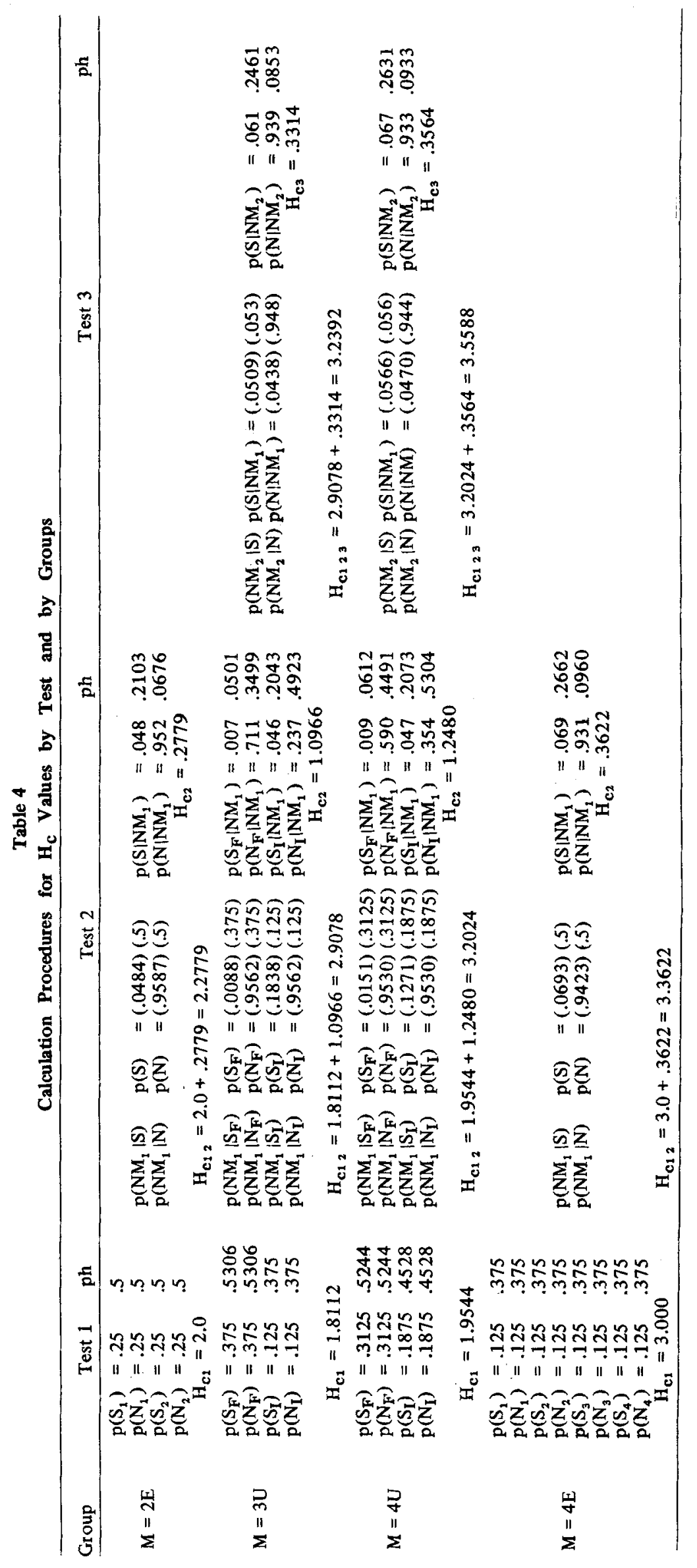


stimulus hypothesis, Test 2 with the negative set hypothesis, and Test 3 with the infrequent positive set stimuli hypothesis, the latter two tests given failure or failures of the preceding test(s). The structure of Test 1 , as shown in Table 4, would appear to involve a test of both the $S_{F}$ and $S_{I}$ hypotheses; however, the much longer reaction times for $S_{I}$ suggest that this was not the case and that such reactions were emitted only after Test 3.

The entries for $p\left(\mathrm{NM}_{1} \mid \mathrm{S}_{\mathrm{F}}\right)$ and $\mathrm{p}\left(\mathrm{NM}_{1} \mid \mathrm{S}_{\mathrm{I}}\right)$ of Test 2 are the contingent probabilities of error listed in Column 6 of Table 2, while 1 - contingent error generated the values of $p\left(N_{1} \mid N_{F}\right)$ and $p\left(N_{1} \mid N_{I}\right)$ for Groups $M=3 U$ and $M=4 U$. This is consistent with the way the Test 2 probabilities were revised for Groups $M=2 E$ and $M=4 E$. The revision of probabilities for Test 3 , however, involves the contingent probabilities directly, not 1 - contingent error. This is because Test 2 is a test of the negative set hypothesis, and so $\mathrm{p}\left(\mathrm{NM}_{2} \mid \mathrm{N}\right)$ is the probability of failing to observe a match between the encoded test stimulus and memorial information of the negative set, thereby leading to a false positive response. The values of $\mathrm{p}\left(\mathrm{NM}_{2} \mid \mathrm{S}\right)$ were obtained by summing number of errors across $S_{I}$ and $S_{F}$ prior to division by the total number of usable positive set stimulus occurrences.

Therefore, there are three values of $\mathrm{H}_{\mathbf{c}}$ for Group $\mathrm{M}=3 \mathrm{U}: 1.8112,2.9078$, and 3.2392 bits for reactions to $S_{F}, N$, and $S_{I}$, respectively. For Group $M=4 U, H_{c}=$ $1.9544,3.2024$, and 3.5588 bits for $S_{F}, N$, and $S_{I}$, respectively. It is now appropriate to determine the extent to which these six values of $H_{c}$, plus the two for reactions to $N$ stimuli by Groups $M=2 E$ and $M=4 E$, are accurate in predicting reaction times through the equation $\mathrm{RT}=.1961+.1001\left(\mathrm{H}_{\mathrm{c}}\right)$. Table 5 summarizes the information presented above along with the errors of prediction when the derived values of $\mathrm{H}_{c}$ are used to obtain predicted reaction times. The algebraic average error of prediction is $+0.7 \mathrm{msec}$, while the standard deviation of the eight errors is $10.9 \mathrm{msec}$. It would appear that a single function, a linear fit to the $S$ data of

Table 5

Calculated Values of $\mathrm{H}_{c}$, Observed, and Predicted Reaction Times

\begin{tabular}{|c|c|c|c|c|c|}
\hline \multirow[b]{2}{*}{ Group } & \multirow{2}{*}{$\begin{array}{c}\text { Test } \\
\text { Stimulus }\end{array}$} & \multirow[b]{2}{*}{$\mathrm{H}_{\mathrm{c}}$} & \multicolumn{2}{|c|}{ Reaction Time } & \multirow{2}{*}{$\begin{array}{l}\text { Error } \\
(\mathrm{Sec})\end{array}$} \\
\hline & & & Observed & Predicted & \\
\hline$M=2 E$ & $\begin{array}{l}\mathrm{S} \\
\mathrm{N}\end{array}$ & $\begin{array}{l}2.0 \\
2.2779\end{array}$ & $\begin{array}{l}.3963 \\
.4277\end{array}$ &.$\overline{241}$ &.$- \overline{-} 36$ \\
\hline$M=3 U$ & $\begin{array}{l}\mathrm{S}_{\mathrm{F}} \\
\mathrm{N} \\
\mathrm{S}_{\mathrm{I}}\end{array}$ & $\begin{array}{l}1.8112 \\
2.9078 \\
3.2392\end{array}$ & $\begin{array}{l}.3729 \\
.4818 \\
.4984\end{array}$ & $\begin{array}{l}.3774 \\
.4872 \\
.5203\end{array}$ & $\begin{array}{l}+.0045 \\
+.0054 \\
+.0219\end{array}$ \\
\hline$M=4 U$ & $\begin{array}{l}S_{\mathrm{F}} \\
\mathrm{N} \\
\mathrm{S}_{\mathrm{I}}\end{array}$ & $\begin{array}{l}1.9544 \\
3.2024 \\
3.5588\end{array}$ & $\begin{array}{l}.4032 \\
.5254 \\
.5432\end{array}$ & $\begin{array}{l}.3917 \\
.5167 \\
.5523\end{array}$ & $\begin{array}{r}-.0115 \\
-.0087 \\
+.0091\end{array}$ \\
\hline$M=4 E$ & $\begin{array}{l}\mathbf{S} \\
\mathbf{N}\end{array}$ & $\begin{array}{l}3.0 \\
3.3622\end{array}$ & $\begin{array}{l}.4964 \\
.5439\end{array}$ & .5327 &.$- \overline{0112}$ \\
\hline
\end{tabular}

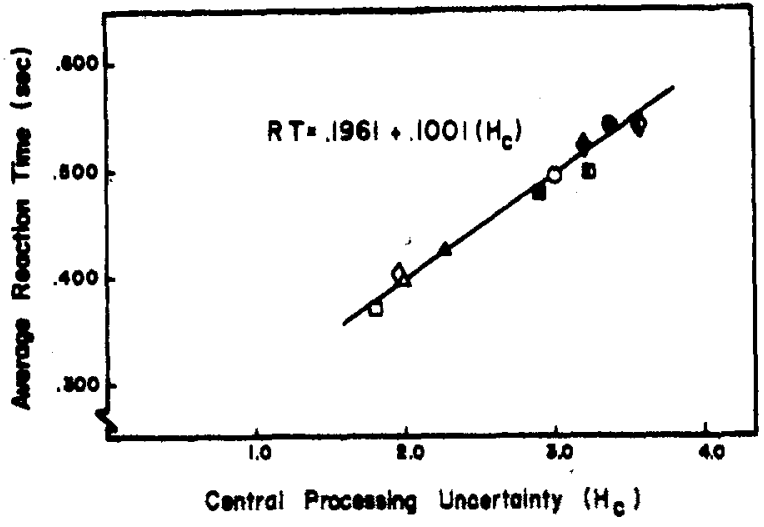

Fig. 2. The reaction time data of Fig. 1 as a function of derived values of $\mathrm{H}_{\mathrm{c}}$.

Groups $M=2 E$ and $M=4 E$, can describe quite accurately the relationship between $\mathrm{H}_{\mathfrak{c}}$ and RT for the $\mathrm{S}_{\mathrm{F}}, \mathrm{N}$, and $\mathrm{S}_{\mathrm{I}}$ data (see Fig. 2).

\section{Stimulus and Response Repetition}

Given the $H_{c}$ values of $1.8112,1.9544,2.0$, and 3.0 bits for the $S_{F}$ and $S$ test stimuli (see Table 5), the positive set reaction time data of Table 3 were fit by the least squares procedure to Eq. 3. Likewise the $\mathrm{H}_{\mathrm{c}}$ values of $2.2779,2.9078,3.2024$, and 3.3622 bits for the $\mathrm{N}$ test stimuli were used to fit the negative set reaction times of Table 3. The results are listed in the top panel of Table 6. First consider the goodness of fit (see Column 3 of the top panel). The range is from 4.3 to only $9.8 \mathrm{msec}$ for the standard errors of prediction. The largest single error of prediction was $15.0 \mathrm{msec}$, and 19 of the 24 individual errors were $10 \mathrm{msec}$ or less. Clearly, the $H_{c}$ values derived as in Table 4 provide good fits not only for the $S, S_{F}, S_{I}$, and $\mathrm{N}$ reaction time averages (see Table 5 ), but also they do so for the $S, S_{F}$, and $N$ data when they are categorized as to stimulus repetition condition.

It is apparent from the top panel of Table 6 that the repetition effects are revealed in both the intercept and the slope constants of Eq. 3. Progressing from Id through $\mathrm{Eq}$ to Diff, the intercept constants decrease while the slope constants increase for both the positive set and the negative set data. Thus, whereas stimulus repetition (Id) involves longer stimulus encoding and/or response decoding time than does stimulus nonrepetition (Eq and Diff), central processing is faster for repeated than for nonrepeated stimuli. If one assumes additivity of stimulus and of response repetition effects, it is possible to use the results of Table 6 to estimate the relative magnitudes of those effects. As shown in the middle panel of Table 6, the intercept constant a of Eq. 3 is assumed to consist of three components: (1) a minimum time for encoding and decoding $(\alpha)$, (2) a component for stimulus repetition $\left(\alpha_{s}\right)$, and (3) a component for response repetition $\left(\alpha_{\mathbf{r}}\right)$. Condition Id involves all three components, Eq involves only $\alpha$ and $\alpha_{\mathrm{r}}$, and Diff involves only $\alpha$. Likewise the slope constant $b$ is 
Table 6

Repetition Effects for Both Positive and Negative Set Stimuli

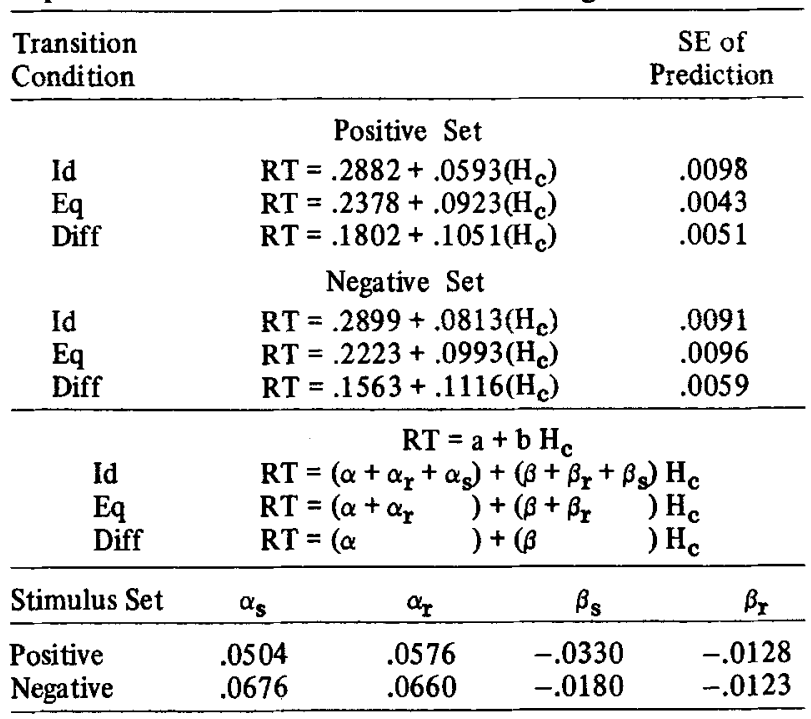

shown to involve three components: (1) a basic cycle time $\beta,(2)$ a component reflecting the influence of stimulus repetition $\left(\beta_{s}\right)$, and (3) a response repetition component $\beta_{\mathbf{r}}$ ).

The bottom panel of Table 6 lists estimates of the stimulus repetition effects $\left(\alpha_{s}\right.$ and $\left.\beta_{s}\right)$ and of the response repetition effects $\left(\alpha_{r}\right.$ and $\left.\beta_{r}\right)$. These estimates come from successive differences between the intercepts and the slopes of the fitted equations in the top panel of Table 6 . It may be recalled that the intercept constant a of Eq. 3 is interpreted as the time to encode stimulus information plus the time to decode a response. It is apparent that the stimulus repetition effect was comparable to the response repetition effect on those processes $\left(\alpha_{\mathbf{s}}\right.$ and $\alpha_{\mathrm{r}}$ are approximately equal within both the positive set and the negative set data). However, the influence of stimulus repetition was greater than that of response repetition on central processing time, much greater in the case of positive set stimuli $(-33 \mathrm{msec}$ vs $-12.8 \mathrm{msec}$ per bit of central processing uncertainty). It remains to be seen if the simplistic additivity model used in Table 6 is a valid expression of the repetition effects. Some research by Kornblum (1973, pp. 276-279) does support the assumption of additivity here. At the present time, then, the pattern of results in Table 6 offers an intriguing suggestion of the loci and of the relative influence of both stimulus and response repetition effects on choice reaction time in an information reduction task.

\section{The Information Hypothesis}

In his classic paper, Hick (1952) noted that for choice reaction times in an information conservation task

$$
\mathrm{RT}=\mathrm{a}+\mathrm{b}\left(\mathrm{H}_{\mathrm{s}}\right)
$$

where $H_{s}$ is a Shannon expression of stimulus uncertainty. Hyman (1953) demonstrated the generality of Eq. 5 by finding that it fits individual subject reaction times when $\mathrm{H}_{\mathrm{s}}$ is varied in any of three ways: (1) by varying the number of equally probable stimuli, the procedure used by Hick, (2) by using stimulus ensembles of differing size and unequal stimulus frequencies, and (3) by using stimulus ensembles of differing size with variation in sequential dependencies among the test stimuli. The information hypothesis stated as Eq. 5 has proved to be a viable description of reaction time data, and it provides the basis for attempts to understand human information processing within the context of a communication model.

Swanson and Briggs (1969) found that for an information reduction task, the comparable additivity statement is

$$
\mathrm{RT}=\mathrm{a}+\mathrm{b}\left(\mathrm{H}_{\mathrm{c}}\right) \text {. }
$$

It may be noted that for an information conservation task, $\mathrm{H}_{\mathrm{c}}=\mathrm{H}_{\mathrm{s}}$; therefore, Eq. 3 would seem to be the more basic statement of the information hypothesis, since it enjoys generality to both information conservation and information reduction tasks. A series of experiments has shown that Eq. 3 can be expanded to more complex statements of additivity by employing independent variables made orthogonal to memory load, e.g., display load (Briggs \& Swanson, 1970; Briggs \& Johnsen, 1973), response load (Briggs \& Swanson, 1970), speed vs accuracy (Swanson \& Briggs, 1969; Lyons \& Briggs, 1971; Briggs \& Shinar, 1972), visual noise (Briggs \& Shinar, 1972), etc. The contribution of the previous research, then, has been in showing how the basic additivity statement can be expanded to express the influence of numerous independent variables on human information processing in an information reduction task. Such expansion was achieved by showing how either the intercept or the slope constant of Eq. 3 was related to average reaction times under the several levels of each independent variable.

The present research is a departure from the previous studies in that here a procedure is explored for deriving different values of $\mathrm{H}_{c}$ itself in response to different levels of test stimulus set and of stimulus probability within the positive set. Basic to the procedure, illustrated in Table 4, is the notion that stimulus classification consists of one or more hypothesis tests. It is important to recognize that the structure of the test cycle as a whole determines the level of the predictor variable. It is meaningless to attempt to relate (predict) reaction times to single stimuli, such as $S_{F}$ in the present study, from the surprisal value (h) of that stimulus or from its average surprisal value (ph). Rather, $-\Sigma \mathrm{ph}$ or average uncertainty (Eq. 2) is the essential basis for expressing the information hypothesis. For example, referring to Group $M=3 U$ in Table 4, the most frequent stimulus occurred with $p\left(S_{F}\right)=.375$. Neither $h=1.415$ nor $\mathrm{ph}=.5306$ bits is of value in predicting the average reaction time to that stimulus as in Eq. 3 . Rather, the 
Table 7

Calculation of $\mathrm{H}_{c}$ Values for the Hyman Data

\begin{tabular}{|c|c|c|c|c|}
\hline Test 1 & $\mathrm{ph}$ & Test $2^{*}$ & & ph \\
\hline \multirow[t]{2}{*}{$\begin{array}{l}\mathrm{p}\left(\mathrm{S}_{\mathrm{F}}\right)=.8125 \\
\mathrm{p}\left(\mathrm{S}_{\mathrm{o}}\right)=.1875\end{array}$} & $\begin{array}{l}.2434 \\
.4528\end{array}$ & $\begin{array}{l}\mathrm{p}\left(\mathrm{NM}_{1} \mid \mathrm{S}_{\mathrm{F}}\right) \mathrm{p}\left(\mathrm{S}_{\mathrm{F}}\right)=(.004)(.8125) \\
\mathrm{p}\left(\left.\mathrm{NM}_{1}\right|_{\mathrm{S}}\right) \mathrm{p}\left(\mathrm{S}_{\mathrm{I}}\right)=(.98)(.0625) \\
\mathrm{p}\left(\left.\mathrm{NM}_{1}\right|_{\mathrm{I}}\right) \mathrm{p}\left(\mathrm{S}_{\mathrm{I}}\right)=(.98)(.0625) \\
\mathrm{p}\left(\mathrm{NM}_{1} \mid \mathrm{S}_{\mathrm{I}}\right) \mathrm{p}\left(\mathrm{S}_{\mathrm{I}}\right)=(.98)(.0625)\end{array}$ & $\begin{array}{l}\mathrm{p}\left(\mathrm{S}_{\mathrm{F}} \mid \mathrm{NM}_{1}\right)=.017 \\
\mathrm{p}\left(\mathrm{S}_{\mathrm{I}} \mid \mathrm{NM}_{1}\right)=.328 \\
\mathrm{p}\left(\mathrm{S}_{\mathrm{I}} \mid \mathrm{NM}_{1}\right)=.328 \\
\mathrm{p}\left(\mathrm{S}_{\mathrm{I}} \mid \mathrm{NM}_{1}\right)=.328\end{array}$ & \multirow[t]{2}{*}{$\begin{array}{r}.0999 \\
.5275 \\
.5275 \\
.5275 \\
\mathrm{H}_{\mathrm{c} 2}=1.6824\end{array}$} \\
\hline & $=.6962$ & \multicolumn{2}{|c|}{$H_{c_{12}}=.6962+1.6824=2.3786$} & \\
\hline
\end{tabular}

${ }^{*}$ Values of $p\left(N M_{1} \mid S_{F}\right)$ and $p\left(N M_{1} \mid S_{1}\right)$ are based on personal communication with Dr. Hyman, who recalled $p(E)=.01$ or less for his highly practiced Ss.

average uncertainty of the test of the hypothesis $S_{F}$, a test relating to a single stimulus, is the proper uncertainty measure to employ, $\mathrm{H}_{\mathrm{c}}=1.8112$ bits in this situation. Reference to Table 5 shows that this value of $\mathrm{H}_{\mathrm{c}}$ was rather accurate in predicting the reaction time to a single test stimulus $S_{F}$, the error of prediction being only $+4.5 \mathrm{msec}$. The $\mathrm{H}_{\mathrm{c}}$ value of $1.9544 \mathrm{bits}$ for the single stimulus $S_{F}$ test of Group $M=4 U$ resulted in a somewhat greater, but nevertheless modest, error of prediction of the reaction time: $-11.5 \mathrm{msec}$. We must therefore take exception to a statement by Garner (1962): "When attempts are made to use uncertainty measures to predict performance to an individual stimulus within a set, the expected relations are not upheld to any great extent [p. 43]." Garner's conclusion was based, in part, on Hyman's (1953) use of surprisal values to predict reaction times via Eq. 5 . Hyman found very large errors of prediction for both a frequent stimulus, $\mathrm{p}\left(\mathrm{S}_{\mathrm{F}}\right)=.8125$, and for the average reaction time of three infrequent stimuli, $\mathrm{p}\left(\mathrm{S}_{\mathrm{I}}\right)=.0625$ each. It is now clear that one can use uncertainty measures to predict performance to an individual stimulus, provided the uncertainty measure reflects the structure of the test of a single stimulus hypothesis, as in Test 1 for Groups $\mathrm{M}=3 \mathrm{U}$ and $\mathrm{M}=4 \mathrm{U}$.

To illustrate, consider the data quoted by Hyman (1953) for Subject GC, Condition 3, Experiment II. It requires two tests to account for the observed $S_{F}$ and $S_{I}$ reaction times of .306 and $.585 \mathrm{sec}$, respectively. Given the very high probability of $S_{F}$, it is assumed that the structure of Test 1 involves a consideration of $S_{F}$ vs the other three possible stimuli as a class, $S_{o}$ (see Table 7). If this test fails, then the structure of Test 2 in Table 7 is similar to Test 2 for Groups $M=3 \mathrm{U}$ and $\mathrm{M}=4 \mathrm{U}$ of Table 4. The values $H_{c 1}=.6962$ bit and $H_{c 12}=$ 2.3786 bits represent the uncertainty involved in the tests of the $S_{F}$ and (if necessary) the $S_{I}$ hypotheses. Hyman (1953) reports the fitted value of Eq. 5 for Subject $\mathrm{GC}$ as $\mathrm{RT}=.212+.153\left(\mathrm{H}_{\mathrm{S}}\right)$. Using the above values of $\mathrm{H}_{\mathrm{c} 1}$ and $\mathrm{H}_{\mathbf{c} 12}$, the predicted reaction times for $\mathrm{S}_{\mathrm{F}}$ and $\mathrm{S}_{\mathrm{I}}$ are .319 and $.576 \mathrm{sec}$, respectively. The errors of prediction are quite modest here: +13 and $-9 \mathrm{msec}$, respectively.
It would appear that the information hypothesis is applicable to both information conservation and information reduction tasks. Further, use of the successive test assumption eliminates an apparent deficiency of the information hypothesis in accounting for single stimulus reaction times.

\section{REFERENCES}

Briggs, G. E., \& Johnsen, A. M. On the nature of central processing in choice reactions. Memory \& Cognition, 1973, 1, 91-100.

Briggs, G. E., \& Shinar, D. On the locus of the speed/accuracy tradeoff. Psychonomic Science, 1972, 28, 326-328.

Briggs, G. E., \& Swanson, J. M. Encoding, decoding, and central functions in human information processing. Journal of Experimental Psychology, 1970, 86, 296-308.

Garner, W. R. Uncertainty and structure as psychological concepts. New York: Wiley, 1962.

Hick, W. E. On the rate of gain of information. Quarterly Journal of Experimental Psychology, 1952, 4, 11-26.

Hyman, $R$. Stimulus information as a determinant of reaction time. Journal of Experimental Psychology, 1953, 45, 188-196.

Kornblum, S. Sequential determinants of information processing in serial and discrete choice reaction time. Psychological Review, $1969,76,113-131$.

Kornblum, S. Sequential effects in choice reaction time: A tutorial review. In S. Kornblum (Ed.), Attention and performance IV. New York: Academic Press, 1973. Pp. 259-288.

Lyons, J. J., \& Briggs, G. E. Speed-accuracy trade-off with different types of stimuli. Journal of Experimental Psychology, 1971, 91, 115-119.

Schvaneveldt, R. W., \& Chase, W. G. Sequential effects in choice reaction time. Journal of Experimental Psychology, 1969, 80, 1-8.

Shannon, C. E. A mathematical theory of communication. Bell System Technical Journal, 1948, 27, 379-423, 623-656.

Smith, E. E. Choice reaction time: An analysis of the major theoretical positions. Psychological Bulletin, 1968, 69, 77-110.

Sternberg. S. High-speed scanning in human memory. Science, $1966,153,652-654$.

Sternberg, S. The discovery of processing stages: Extensions of Donders' method. Acta Psy chologica, 1969, 30, 276-315.

Swanson, J. M., \& Briggs, G. E. Information processing as a function of speed versus accuracy. Journal of Experimental Psychology, 1969, 81, 223-229.

Theios, J. Stimulus and response probability and sequential effects in memory scanning. Paper read at the Midwestern Psychological Association meeting, May 1973, Chicago.

Theios, J., Smith, P. G., Haviland, S. E., Traupmann, J., \& Moy, M. C. Memory scanning as a serial self-terminating process. Journal of Experimental Psychology, 1973, 97, 323-336.

(Received for publication October 19, 1973; accepted November 14, 1973.) 